\title{
A Novel Surgical Technique to Repair Supra Valvular Pulmonary Stenosis After Arterial Switch Operation for TGA
}

\section{(1) Öztekin Oto}

Dokuz Eylül University Faculty of Medicine, Department of Cardiovascular Surgery, İzmir, Turkey

\section{Introduction}

The incidence of supravalvar pulmonary stenosis has been reported as $17 \%$ to $55 \%$ after the arterial switch operation (ASO) for transposition of great arteries ${ }^{(1,2)}$. Accordingly, the most common indication for reoperation that has been reported among the ASO cases appears to be right ventricular outflow tract obstruction (RVOTO) $)^{(1,3)}$. The operative mortality rate was reported relatively high for the reoperations for supravalvar pulmonary stenosis after ASO for transposition of the great arteries (TGA) in standard techniques ${ }^{(3,4)}$. The most important complication in classical technique is high risk of bleeding during the resternotomy and the need of exploration of neo-aorta. Since neo-aorta occurs posterior to the pulmonary artery and is usually very strictly adherent to the surrounding tissue, full mobilization of neo-aorta for cross-clamping and delivering cardioplegia carries high surgical risk in classical techniques. With this new technique that we have applied in two consecutive patients, the whole operation was carried out in a beating heart status without the exploration of neo-aorta from its districtly adherent surrounding tissues.

We report here a successful novel beating heart technique with iliac arterial venous cannulation before sternotomy in three children to prevent possible bleeding or damage to any cardiac tissue including neo-aorta due to adhesions.

The first case was five years old male with severe supravalvar pulmonary stenosis with $90 \mathrm{mmHg}$ gradient who had ASO on the second day of life. He was successfully operated with this technique and was discharged from the hospital on $10^{\text {th }}$ postoperative day with no complications. He was suffering from mild cyanosis and short of breath on exercise and was totally asymptomatic at discharge from the hospital with no supravalvar pulmonary gradient.

\footnotetext{
Address for Correspondence: Öztekin Oto, Dokuz Eylül University Faculty of Medicine, Department of Cardiovascular Surgery, İzmir, Turkey

e-mail: oztekinoto@oztekinoto.com ORCID: orcid.org/0000-0002-8595-6006

Received: 02.12.2021 Accepted: 02.02.2022

Cite this article as: Oto Ö. A Novel Surgical Technique to Repair Supra Valvular Pulmonary Stenosis After Arterial Switch Operation for TGA. EJCM 2022;10(1):44-46.

DOI: 10.32596/ejcm.galenos.2022.2021-12-064

${ }^{\circ}$ Copyright 2022 by Heart and Health Foundation of Turkey (TÜSAV) / E Journal of Cardiovascular Medicine published by Galenos Publishing House.
} 
The second case was 3 years old male, admitted to the hospital with dyspnea 3 years after Arterial Switch operation for TGA, while one day old. At the echocardiography supravalvar pulmonary gradient of 128 mmHg. Having performed the same operation on beating heart, the patient left the intensive care unit on the second day. He was discharged on $15^{\text {th }}$ postoperative day with no symptoms. He is doing well at clinical follow-up of two and half years.

The third case that is presented here by video with this novel technique developed $75 \mathrm{~mm}$ High gradient at echocardiography on ten and a half month of age who had ASO at the second day of his life. Also, severe tricuspid regurgitation was found at echocardiography that explained the vomiting and malnutrition complaints of the baby for admission to hospital. Therefore, we decided to reoperate the child for both severe supravalvar pulmonary stenosis, as well as tricuspid regurgitation to avoid any possible rupture of the anterior wall of the heart and bleeding, we put the patient on cardiopulmonary bypass as we did in the other two previous cases before starting sternotomy. The novel part of this technique includes not only peripheral cannulation but also a beating heart enlargement of supravalvar stenosis and repair of tricuspid regurgitation as in three of the cases. Due to their older age (five and three) the previous cases allowed us femoral and venous arterial cannulation, whereas here we needed to iliac vessels with retroperitoneal incision.

In fact, this peripheral cannulation technique is a standard for minimally invasive route that we have developed as a routine for reoperations in last ten years to download the heart before sternotomy, as well as to manage better in case of any cardiac tear accidentally occurs. After the exposure of right iliac vessels, we still cannulate them using Seldinger Technique to allow distal arterial and venous flow ${ }^{(5)}$.

Having performed the sternotomy and exposure of the pulmonary arterial trunk and branches with a limited dissection of adhesions a rigid right angle cannulation to superior vena cava was also added superior and inferior venae cava was snared to establish total cardiopulmonary bypass to prevent venous return to the right ventricle.

After clear exposure of severe stenotic pulmonary artery, a small incision was made to allow to insert the venting cannula into the right ventricle, which allowed to complete the incision on the extremely narrowed pulmonary artery until the pulmonary valve on proximal and normal part of distal pulmonary artery. At this stage, the second venting cannula was inserted into the distal pulmonary artery to have bloodless exposure on a beating heart condition to perform neat commissurotomy to pulmonary valve. An additional Hegar dilatation was also performed to reach the target size of the pulmonary valve in proportion to the age and weight of the baby (size 10). Then, to enlarge the suprapulmonary stenosis bovine pericardium was tailored to reach the target pulmonary size according to the weight and age of the baby. Bovine pericardium was sutured with continuous technique and 7-0 pyroline suture under clear bloodless exposure on the beating heart. At the very last suture of anastomosis the venting cannulas were taken out and bleeding control carried out carefully after the completion of the anastomosis.

Then, to start the second part of the operation on a beating heart with snared vena cava, right atrium incised vertically to expose tricuspid valve. Again, a venting cannula was inserted into the right ventricle and the right atrial wall was retracted by using hanging sutures and the rigid retractor to expose tricuspid valve. Coronary sinus blood flow was continuously aspirated with pump suction continuously to have completely bloodless exposure during the modified de Vega annuloplasty sutures. Tightening of the annuloplasty sutures was performed over a $19 \mathrm{~mm}$ size Hegar dilatator to avoid any unintended tricuspid stenosis.

The patient had no complications after surgery and was discharged from the hospital on the seventh postoperative day with no vomiting and nutritional problem.

Although repetitive catheter interventions have been tried as a first choice in many centers, reoperation for RVOTO remains the most common reason amongst the reoperations after ASO for $\mathrm{TGA}^{(3,4,6)}$. 
Since the mortality rate has been reported as a considerably high, three consecutive three successful relief of RVOTO with this novel technique has encouraged us to publish the first three editions of these operations ${ }^{(3,4,7)}$.

\section{Conclusion}

The successful novel beating heart technique with iliac arterial venous cannulation before sternotomy in three children to prevent possible bleeding or damage to any cardiac tissue including neo-aorta due to adhesions is presented here. Considering these three cases, this novel technique seems a safe and effective solution to relieve the supravalvular pulmonary stenosis in postoperative arterial switch operation in TGA.

Video Link: https://youtu.be/j4naiYS9KI8

\section{Ethics}

Ethics Committee Approval: Not needed for this study.

Informed Consent: Informed consent was obtained from the patient.

Peer-review: Externally peer-reviewed.
Financial Disclosure: The author declared that this study received no financial support.

\section{References}

1. Vitanova K, Pabst von Ohain J, Ono M, et al. Incidence and Risk Factors for Right Ventricular Outflow Tract Obstruction after the Arterial Switch Operation. Thorac Cardiovasc Surg 2019;67:37-43.

2. Swartz MF, Sena A, Atallah-Yunes N, et al. Decreased Incidence of Supravalvar Pulmonary Stenosis After Arterial Switch Operation. Circulation, 2012;126(11_suppl_1), S118-22.

3. Bokenkamp R, Aguilar E, van der Palen RL, et al. Reoperation for right ventricular outflow tract obstruction after arterial switch operation for transposition of the great arteries and aortic arch obstruction. Eur J Cardiothorac Surg 2016;49:e91-6.

4. van der Palen RLF, Blom NA, Kuipers IM, et al. Long-term outcome after the arterial switch operation: 43 years of experience. Eur J Cardiothorac Surg 2021;59:968-7.

5. Gençpınar T, Sayarer C, Akkaya G, Oto Ö. Outcomes of with open and Seldinger-Guided Peripheral Cannulation Techniques in open heart surgery. E J Cardiovasc Med 2018;6:7-14

6. Nellis JR, Turek JW, Aldoss OT, Atkins DL, Ng BY. Intervention for supravalvar pulmonary stenosis after the arterial switch operation. Ann Thorac Surg 2016;102:154-62

7. Vargo P, Mavroudis C, Stewart RD, Backer CL. Late complications following the arterial switch operation. World J Pediatr Congenit Heart Surg 2011;2:37-42. 